\title{
Optimal Vibration Control for Half-Car Suspension on In-Vehicle Networks in Delta Domain
}

\author{
Jing Lei, ${ }^{1,2}$ Shun-Fang Hu, ${ }^{1}$ Zuo Jiang, ${ }^{1,2,3}$ and Guo-Xing Shi ${ }^{1}$ \\ ${ }^{1}$ School of Mathematics and Computer Science, Yunnan Nationalities University, Kunming 650500, China \\ ${ }^{2}$ Key Laboratory in Software Engineering of Yunnan Province, Kunming 650091, China \\ ${ }^{3}$ National Pilot School of Software, Yunnan University, Kunming 650091, China \\ Correspondence should be addressed to Jing Lei; elizabethia@126.com
}

Received 3 January 2013; Accepted 18 February 2013

Academic Editor: Valery Y. Glizer

Copyright (C) 2013 Jing Lei et al. This is an open access article distributed under the Creative Commons Attribution License, which permits unrestricted use, distribution, and reproduction in any medium, provided the original work is properly cited.

\begin{abstract}
The paper explores the optimal vibration control design problem for a half-car suspension working on in-vehicle networks in delta domain. First, the original suspension system with ECU-actuator delay and sensor-ECU delay is modeled. By using delta operators, the original system is transformed into an associated sampled-data system with time delays in delta domain. After model transformation, the sampled-data system equation is reduced to one without actuator delays and convenient to calculate the states with nonintegral time delay. Therefore, the sampled-data optimal vibration control law can be easily obtained deriving from a Riccati equation and a Stein equation of delta domain. The feedforward control term and the control memory terms designed in the control law ensure the compensation for the effects produced by disturbance and actuator delay, respectively. Moreover, an observer is constructed to implement the physical realizability of the feedforward term and solve the immeasurability problem of some state variables. A half-car suspension model with delays is applied to simulate the responses through the designed controller. Simulation results illustrate the effectiveness of the proposed controller and the simplicity of the designing approach.
\end{abstract}

\section{Introduction}

In the past years, communication networks have been applied greatly and widely into the advanced vehicle systems, such as electronic control units (ECUs), sensors, and actuators which are all connected over the high-speed in-vehicle networks (IVNs), for example, Local Interconnect Network, Controller Area Network, Media Oriented Systems Transport [1-3], and so forth. However, in this kind of IVNs, two important issues emerge for the controller design problems. One is the network-induced delay issue. Over communication networks, the time delays generated between sensor-controller, controller-actuator, ECU computation delay, and so forth are unavoidably encountered. As well known, even a small time delay can make the systems disastrously unstable or generate oscillations [4-6]. So, this issue should be taken into account when we design a controller for a system over networks. The next issue is the system modeling problem. Actually, signals processed by microprocessors are digital, and most of those produced by sensors or put into actuators are analogs. Thus, the continuous-time plant is combined with a discrete-time controller, where $\mathrm{A} / \mathrm{D}$ and $\mathrm{D} / \mathrm{A}$ converts are used to combine these two different signals. Therefore, a sampled-data system is more appropriate for the reality of networked-control system. In previous studies, there are two main approaches to get the sampled-data systems, those are, indirect approach of continuous-time domain and direct approach of discrete-time domain. However, the former is only suitable for simple control algorithms, and the latter has two drawbacks: one is that the discrete-time model is unable to approach to its corresponding continuous-time one as the sampling frequency increases; and the other is that the discretized system can cause oscillations and unstable phenomenon as the sampling frequency increases.

Consequentially, we present two strategies to deal with these above-mentioned issues. First, we introduce the delta operator approach to build a sampled-data model for the networked-control system due to its accurate approximation 
to the continuous-time model under rapid sampling conditions [7-11]. This advantage can be demonstrated by citing an instance.

Consider a continuous-time system consisted of $(A, B)$ in the state-space representation. The associated discrete-time system can be got as $\left(A_{z}, B_{z}\right)$ with $A_{z}=\mathrm{e}^{A T}, B_{z}=\int_{0}^{T} \mathrm{e}^{A t} \mathrm{~d} t B$, and $T$ the sampling period. Alternatively, the associated sampled-data system in delta domain is $\left(A_{\delta}, B_{\delta}\right)$ with $A_{\delta}=$ $\left(A_{z}-I\right) / T, B_{\delta}=B_{z} / T$, and $I$ a unit matrix. Apparently, $A_{z} \rightarrow I, B_{z} \rightarrow 0$ and $A_{\delta} \rightarrow A, B_{\delta} \rightarrow B$ while $T \rightarrow 0$.

From this instance, it is clear that the discrete-time model cannot approximate to its original continuous-time one when sampling fast. On the contrary, the delta-domain sampleddata one enables approximating to the continuous accurately. See that this is our reason to apply the delta operators approach modeling a sampled-data system for an IVNs-based suspension.

The other contribution of this paper is developing the model transformation method [11-13] to solve optimal vibration control (OVC) design problem for sampled-data systems with time delays in delta domain. The model transformation method is based on the finite spectrum assignment methodology [14], and we have developed it solving the OVC design problems for time-delay systems in continuous-time domain or in discrete-time domain. It was proved able to transform the original time-delay system into a delay-free one such that the original solution problem is reduced from an infinitedimension space to a finite-dimension space, and so that the controller design problem is greatly simplified [11-14].

In brief, as a result, the obtained control law in this paper consists of a feedforward term and some control memory terms which can be stored in memories beforehand. Hence, the persistent road excitation suffered by suspension can be reduced via the feedforward term, and the time-delay effect of the system can be compensated by the control memory terms. At last, we carry out some simulations to validate the effectiveness and the simplicity of the designed OVC comparing with the open-loop system (OLS).

The paper's organization displays as follows. After this introduction of Section 1, in Section 2, the system description and problem formulation have been done. In Section 3, the OVC is designed accompanied with the observer-based control law design. Numerical examples are simulated in Section 4. Concluding remarks are given in Section 5.

\section{Problem Statement}

2.1. System Modeling. Consider a four-degree-of-freedom half-car model (refered to in [15]) where the suspension motion is determined by the following dynamic equations:

$$
\begin{aligned}
& I \ddot{\phi}(t)+l_{f} k_{f}\left[x_{s f}(t)-x_{u f}(t)\right]+l_{r} k_{r}\left[x_{s r}(t)-x_{u r}(t)\right] \\
& \quad+l_{f} b_{f}\left[\dot{x}_{s f}(t)-\dot{x}_{u f}(t)\right]+l_{r} k_{r}\left[\dot{x}_{s r}(t)-\dot{x}_{u r}(t)\right] \\
& =l_{f} u_{f}(t-\tau)+l_{r} u_{r}(t-\tau), \\
& -m_{u f} \ddot{x}_{u f}(t)+k_{f}\left[x_{s f}(t)-x_{u f}(t)\right]-k_{t f}\left[x_{u f}(t)-x_{r f}(t)\right] \\
& \quad+b_{f}\left[\dot{x}_{s f}(t)-\dot{x}_{u f}(t)\right]=u_{f}(t-\tau), \\
& -m_{u r} \ddot{x}_{u r}(t)+k_{r}\left[x_{s r}(t)-x_{u r}(t)\right]-k_{t r}\left[x_{u r}(t)-x_{r r}(t)\right] \\
& \quad+b_{r}\left[\dot{x}_{s r}(t)-\dot{x}_{u r}(t)\right]=u_{r}(t-\tau),
\end{aligned}
$$

through Newton-Euler method. In this half-car suspension model, the sprung mass $m_{s}$ and unsprung one $m_{u}$ are separated by spring, damper, and actuator, which are placed in parallel. The tire of the vehicle is modeled as a spring. Vertical motion $x_{c}(t)$ and pitch motion $\phi(t)$ of the sprung mass are considered, as well as the vertical motion of the front unsprung mass $x_{u f}(t)$ and the rear one $x_{u r}(t)$.

Consider it working on an IVNs-based environment, as depicted in Figure 1, where $x, u$, and $y_{m}$ denote the system state, control input, and measured output, respectively; $v$ is the road excitation input; $\tau, \sigma$ are constant ECU-actuator delay and sensor-ECU delay, respectively, (actuator delay and sensor delay for short) which are always assumed to be known and constant in such IVNs environment.

With the purpose of replacing (1) into the state-space representation, define the state, control, and disturbance vectors as

$$
\begin{gathered}
x(t)=\left[x_{s f}(t)-x_{u f}(t), x_{s r}(t)-x_{u r}(t),\right. \\
x_{u f}(t)-x_{r f}(t), x_{u r}(t)-x_{r r}(t), \\
\left.\dot{x}_{s f}(t), \dot{x}_{s r}(t), \dot{x}_{u f}(t), \dot{x}_{u r}(t)\right]^{T}, \\
u(t)=\left[u_{f}(t), u_{r}(t)\right]^{T}, \\
v(t)=\left[\dot{x}_{r f}(t), \dot{x}_{r r}(t)\right]^{T},
\end{gathered}
$$

the controlled output vector as

$$
\begin{aligned}
y_{c}(t)= & {\left[\ddot{x}_{c}(t), \ddot{\phi}(t), x_{s f}(t)-x_{u f}(t), x_{s r}(t)-x_{u r}(t),\right.} \\
& \left.x_{u f}(t)-x_{r f}(t), x_{u r}(t)-x_{r r}(t)\right]^{T} \\
= & {\left[\ddot{x}_{c}(t), \ddot{\phi}(t), x_{1}(t), x_{2}(t), x_{3}(t), x_{4}(t)\right]^{T}, }
\end{aligned}
$$




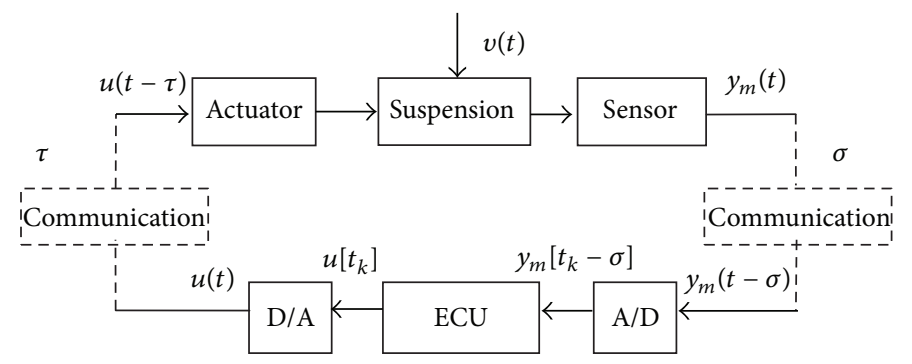

FIGURE 1: Suspension system working on IVNs.

and the measured output vector as

$$
\begin{aligned}
y_{m}(t)= & {\left[x_{s f}(t-\sigma)-x_{u f}(t-\sigma),\right.} \\
& \left.x_{s r}(t-\sigma)-x_{u r}(t-\sigma), \dot{x}_{s f}(t-\sigma), \dot{x}_{s r}(t-\sigma)\right]^{T} \\
= & {\left[x_{1}(t-\sigma), x_{2}(t-\sigma), x_{5}(t-\sigma), x_{6}(t-\sigma)\right]^{T} . }
\end{aligned}
$$

Together with the associated dynamic equations

$$
\begin{aligned}
& x_{s f}(t)=x_{c}(t)+l_{f} \phi(t), \\
& x_{u r}(t)=x_{c}(t)-l_{r} \phi(t)
\end{aligned}
$$

and the definitions (2)-(4), the system (1) thus is rewritten in the state-space representation as

$$
\begin{gathered}
\dot{x}(t)=A x(t)+B u(t-\tau)+D v(t), \\
y_{m}(t)=C_{1} x(t-\sigma), \\
y_{c}(t)=C_{2} x(t)+E u(t-\tau), \\
x(t)=\alpha(t), \quad t \in[-\sigma, 0], \\
u(t)=0, \quad t \in[-\tau, 0),
\end{gathered}
$$

with $x(t) \in \mathbb{R}^{8}, u(t) \in \mathbb{R}^{2}, y_{m}(t) \in \mathbb{R}^{4}$, and $y_{c}(t) \in \mathbb{R}^{6}$ as the state vector, control output, measurement vector, and controlled output, respectively, $A, B, C_{1}, C_{2}, D$, and $E$ as the real constant matrices of appropriate dimensions, and $\alpha(t) \epsilon$ $\mathbf{C}\left([-\sigma, 0] ; \mathbb{R}^{8}\right)$ as the initial state vector.

Consequently, the sampled-data system form of the system (6) can be got by applying the sampled-data controller where there is a zero-order holder

$$
\begin{gathered}
u(t)=u\left[t_{k}\right], \quad t \in\left[t_{k}, t_{k+1}\right), \\
u\left[t_{k}\right]=u\left(K x\left(t_{k-h_{2}-d_{2}}\right)\right), \quad k \in \mathbb{N}_{0}, \\
u\left[t_{k}\right]=0, \quad k<0,
\end{gathered}
$$

with $\left\{t_{k}\right\}$ as the sampling times, $x\left(t_{k}\right)$ as the state on time of $t_{k}=k T$, and $K$ as a constant data controller gain, denoting the actuator delay $\tau=h_{1} T+d_{1} T$ and the sensor delay $\sigma=$ $h_{2} T+d_{2} T$ with $h_{i} \in \mathbb{N}$ and $0 \leq d_{i}<1(i=1,2)$. Notice that the delays are expressed in either integers or nonintegers. Then, the sampled-data system of (1) can be described by

$$
\begin{gathered}
\dot{x}(t)=A x(t)+B u\left(t_{k-h_{1}-d_{1}}\right)+D v(t), \\
y_{m}(t)=C_{1} x\left(t_{k-h_{2}-d_{2}}\right), \\
y_{c}(t)=C_{2} x(t)+E u\left(t_{k-h_{1}-d_{1}}\right), \quad t \in\left[t_{k}, t_{k+1}\right), \\
u\left(t_{k-h_{1}-d_{1}}\right)=u\left(K x\left(t_{k-h-d}\right)\right),
\end{gathered}
$$

where $h=h_{1}+h_{2}$ and $d=d_{1}+d_{2}$. Here, the triple $\left(A, B, C_{1}\right)$ is assumed to be completely controllable and observable.

Further, the sampled-data system (8) will be converted to delta domain and without actuator delays. There are two situations that should be considered concerning the nonintegral part $d$ of the time delay: $d \in[0,1]$ and $d \in[1,2]$. However, the derivation procedures of these two situations are similar. So, for the sake of simplicity, the derivation procedure of the former situation will be presented in what follows.

Introducing the delta operator as

$$
\delta(\cdot)\left(t_{k-d_{2}}\right) \triangleq \begin{cases}\frac{(\cdot)\left(t_{k+1-d_{2}}\right)-(\cdot)\left(t_{k-d_{2}}\right)}{T}, & T \neq 0 \\ \frac{\mathrm{d}(\cdot)(t)}{\mathrm{d} t}, & T=0\end{cases}
$$

and letting $t=\left(k+1-d_{2}\right) T$ and $t_{0}=\left(k-d_{2}\right) T$ discretize the sampled-data system (8) in the delta-domain form

$$
\begin{gathered}
\delta x\left(t_{k-d_{2}}\right)=\bar{A} x\left(t_{k-d_{2}}\right)+B_{1} u\left[t_{k-h_{1}}\right] \\
+B_{2} u\left[t_{k-h_{1}-1}\right]+\bar{D} v\left(t_{k-d_{2}}\right), \\
x\left(t_{-d_{2}}\right)=\alpha_{0}, \\
y_{m}\left(t_{k}\right)=C_{1} x\left(t_{k-h_{2}-d_{2}}\right), \\
y_{c}\left(t_{k-d_{2}}\right)=C_{2} x\left(t_{k-d_{2}}\right)+E u\left[t_{k-h_{1}-1}\right] .
\end{gathered}
$$

Noting that the system (10) is the delta-domain sampleddata system with actuator delays, for the convenience of calculation, it will be transformed without actuator delays using the model transformation approach. From the first 
difference equation in (10), it follows the analytical expression of state response

$$
\begin{aligned}
x\left(t_{k-d_{2}}\right)= & A_{z}^{k} x\left(t_{-d_{2}}\right)+\sum_{j=0}^{k-1} A_{z}^{k-1-j} \bar{B} u\left[t_{j}\right] \\
& +\sum_{j=0}^{k-1} A_{z}^{k-1-j} D_{z} v\left(t_{j-d_{2}}\right)-\sum_{j=k-h_{1}}^{k-1} A_{z}^{k-1-j} \bar{B}_{1} u\left[t_{j}\right] \\
& -\sum_{j=k-h_{1}-1}^{k-1} A_{z}^{k-1-j} \bar{B}_{2} u\left[t_{j}\right]
\end{aligned}
$$

where

$$
\begin{aligned}
& \bar{A}=\frac{A_{z}-I}{T}, \quad B_{1}=\frac{B_{z 1}}{T}, \quad B_{2}=\frac{B_{z 2}}{T}, \\
& \bar{D}=\frac{D_{z}}{T}, \quad A_{z}=\mathrm{e}^{A T}, \quad \bar{B}=\bar{B}_{1}+\bar{B}_{2}, \\
& \bar{B}_{1}=A_{z}^{-h_{1}} B_{z 1}, \quad \bar{B}_{2}=A_{z}^{-h_{1}-1} B_{z 2} \\
& B_{z 1}=\int_{0}^{(1-d) T} \mathrm{e}^{A s} \mathrm{~d} s B, \quad B_{z 2}=\int_{(1-d) T}^{T} \mathrm{e}^{A s} \mathrm{~d} s B, \\
& D_{z}=\int_{0}^{T} \mathrm{e}^{A s} \mathrm{~d} s D .
\end{aligned}
$$

Consequently, define a new state vector as

$$
\begin{aligned}
z\left(t_{k-d_{2}}\right)= & x\left(t_{k-d_{2}}\right)+\sum_{i=k-h_{1}}^{k-1} A_{z}^{k-1-i} \bar{B}_{1} u\left[t_{i}\right] \\
& +\sum_{j=k-h_{1}-1}^{k-1} A_{z}^{k-1-j} \bar{B}_{2} u\left[t_{j}\right] .
\end{aligned}
$$

Equation (10) yields the analytical expression of state response for the transformed system

$$
\begin{gathered}
z\left(t_{k-d_{2}}\right)=A_{z}^{k} z\left(t_{-d_{2}}\right)+\sum_{m=0}^{k-1} A_{z}^{k-1-m} \bar{B} u\left[t_{m}\right] \\
+\sum_{l=0}^{k-1} A_{z}^{k-1-l} D_{z} v\left(t_{l-d_{2}}\right), \\
z\left(t_{-d_{2}}\right)=\alpha_{0},
\end{gathered}
$$

with $\bar{C}_{1}=C_{1} A_{z}^{-h_{2}}$, the output equations of the transformed system are got as follows

$$
\begin{aligned}
\bar{y}_{m}\left(t_{k}\right) & =\bar{C}_{1} z\left(t_{k-d_{2}}\right), \\
\bar{y}_{c}\left(t_{k-d_{2}}\right) & =C_{2} z\left(t_{k-d_{2}}\right) .
\end{aligned}
$$

Then, the state equation (15) and the output equation (17) consist the transformed equivalent sampled-data system in delta domain without actuator delays:

$$
\begin{gathered}
\delta z\left(t_{k-d_{2}}\right)=\bar{A} z\left(t_{k-d_{2}}\right)+\bar{B} u\left[t_{k}\right]+\bar{D} v\left(t_{k-d_{2}}\right), \\
z\left(t_{-d_{2}}\right)=\alpha_{0}, \\
\bar{y}_{m}\left(t_{k}\right)=\bar{C}_{1} z\left(t_{k-d_{2}}\right), \\
\bar{y}_{c}\left(t_{k-d_{2}}\right)=C_{2} z\left(t_{k-d_{2}}\right) .
\end{gathered}
$$

Furthermore, the road excitation should be described by an exosystem in delta domain in order to employ the statespace representation designing the OVC.

2.2. Road Disturbance Modeling. According to ISO 2631 standards, the road displacement power spectral density (PSD) is usually approximately represented in the formulation of

$$
S(\Omega)=C_{s} \Omega^{-2}=4^{k} \times 10^{-7} \cdot \Omega^{-2},
$$

$$
\begin{gathered}
\delta z\left(t_{k-d_{2}}\right)=\bar{A} z\left(t_{k-d_{2}}\right)+\bar{B} u\left[t_{k}\right]+\bar{D} v\left(t_{k-d_{2}}\right), \\
z\left(t_{-d_{2}}\right)=\alpha_{0} .
\end{gathered}
$$

with $\Omega$ as the spatial frequency, $C_{s}$ as the road roughness constant, and $k$ as the sort of the road as shown in Table 1. 
TABLE 1: Road grades and PSDs.

\begin{tabular}{lccccc}
\hline Road grade & A & B & C & D & E \\
\hline$C_{s}\left(\times 10^{-7} \mathrm{~m}^{3} / \mathrm{rad}\right)$ & 1 & 4 & 16 & 64 & 245 \\
Road sort $k$ & 0 & 1 & 2 & 3 & 4 \\
\hline
\end{tabular}

Due to the low-pass-filter characteristic of vehicle tires and suspension, the road displacement $x_{r i}(t)(i=f, r)$ can be approximately simulated by a finite Fourier series sum

$$
x_{r i}(t)=\sum_{j=1}^{p} \xi_{j}(t) \triangleq \sum_{j=1}^{p} \phi_{j} \sin \left(\omega_{j} t+\theta_{j}\right)
$$

where $\phi_{j}=2^{k} / 10^{3} j \sqrt{l / 10 \pi}$ are the amplitudes, $\omega_{j}=j \omega_{0}$ are the frequencies with the time frequency internal $\omega_{0}=$ $2 \pi v_{0} / l, \theta_{j}$ are the random phases which follow a uniform distribution in $[0,2 \pi), v_{0}$ is a constant horizontal velocity, $l$ is the given road segment length, and positive integer $p$ limits the considered frequency band.

Letting the disturbance state vector

$w(t)$

$$
=\left[\xi_{1}(t), \xi_{2}(t), \ldots, \xi_{p}(t), \dot{\xi}_{1}(t), \dot{\xi}_{2}(t), \ldots, \dot{\xi}_{p}(t)\right]^{T} \in \mathbb{R}^{p},
$$

the road velocity $v(t)=\left[\dot{x}_{r f}(t), \dot{x}_{r r}(t)\right]^{T}$ then is described by the exosystem

$$
\begin{gathered}
\dot{w}(t)=G w(t), \\
v(t)=F w(t)
\end{gathered}
$$

with

$$
\begin{gathered}
G=\left[\begin{array}{rr}
\mathbf{0} & \mathbf{I}_{p} \\
G_{1} & \mathbf{0}
\end{array}\right] \in \mathbb{R}^{2 p \times 2 p}, \\
G_{1}=\operatorname{diag}\left\{-\omega_{1}^{2},-\omega_{2}^{2}, \ldots,-\omega_{p}^{2}\right\} \in \mathbb{R}^{p \times p}, \\
F=\left[\begin{array}{cccc}
\mathbf{0}_{p} & 1 & \cdots & 1 \\
\mathbf{0}_{p} & 1 & \cdots & 1
\end{array}\right] \in \mathbb{R}^{2 \times 2 p},
\end{gathered}
$$

in which $\mathbf{0}$ and $\mathbf{I}_{p}$ represent the zero matrix and the $p$ order identity matrix, respectively. Using delta operator (9), exosystem (22) is transformed into the delta-domain form

$$
\begin{gathered}
\delta w\left(t_{k-d_{2}}\right)=\bar{G} w\left(t_{k-d_{2}}\right), \\
v\left(t_{k-d_{2}}\right)=F w\left(t_{k-d_{2}}\right), \\
v\left(t_{k}\right)=0, \quad k<0,
\end{gathered}
$$

where $\bar{G}=\left(\mathrm{e}^{G T}-I\right) / T$.

Hence, both the original system and the exosystem are transformed into the delta-domain sampled-data systems so that we would design the OVC for them.
2.3. Problem Formulation. The principal variables for the evaluation of the suspension system are sprung mass acceleration $\ddot{x}_{c}$ and $\ddot{\phi}$ determining the ride comfort, suspension deflection $x_{s i}-x_{u i}$ indicating the limit of vehicle body motion, and tire deflection $x_{u i}-x_{r i}$ ensuring the road holding ability. The purpose is to reduce the acceleration of vehicle body and decrease the dynamic tire forces for improving the road holding ability and the stability of vehicles facing road excitation.

In practice, control $u$ and controlled output $y_{c}$ are unable synchronously zero so that the general infinite-horizon performance index is not convergent. In this case, an average infinite-horizon performance index could be chosen as

$$
J(\cdot)=\lim _{N \rightarrow \infty} \frac{1}{N} \sum_{k=0}^{N}\left[z^{T}\left(t_{k-d_{2}}\right) Q z\left(t_{k-d_{2}}\right)+u^{T}\left[t_{k}\right] R u\left[t_{k}\right]\right]
$$

with $Q=C_{2}^{T} Q_{0} C_{2}, Q_{0}=\operatorname{diag}\left\{q_{i}\right\}(i=1,2, \ldots, 6)$ as positive semidefinite matrices and $R=\operatorname{diag}\left\{r_{j}\right\} \quad(j=1,2)$ as a positive definite matrix, assuming that $C^{T} C=Q$ with $C$ an arbitrary matrix and the triple $(\bar{A}, \bar{B}, C)$ completely controllable and observable.

Remark 1. When $d \in[1,2]$, the delta-domain sampled-data system is described by

$$
\begin{array}{r}
\delta x\left(t_{k-d_{2}}\right)=\bar{A} x\left(t_{k-d_{2}}\right)+B_{1} u\left[t_{k-h_{1}-1}\right] \\
+B_{2} u\left[t_{k-h_{1}-2}\right]+\bar{D} v\left(t_{k-d_{2}}\right), \\
x\left(t_{-d_{2}}\right)=\alpha_{0}, \\
y_{m}\left(t_{k}\right)=C_{1} x\left(t_{k-h_{2}-d_{2}}\right), \\
y_{c}\left(t_{k-d_{2}}\right)=C_{2} x\left(t_{k-d_{2}}\right)+E u\left[t_{k-h_{1}-2}\right],
\end{array}
$$

with

$$
B_{1}=\frac{1}{T} \int_{0}^{(d-1) T} \mathrm{e}^{A s} \mathrm{~d} s B, \quad B_{2}=\frac{1}{T} \int_{(d-1) T}^{T} \mathrm{e}^{A s} \mathrm{~d} s B
$$

The derivation procedure of this situation is similar to that of $d \in[0,1]$. It is omitted for the simplification reason.

\section{Optimal Vibration Controller Design}

\subsection{Sampled-Data OVC Design}

Theorem 2. Consider the optimal vibration control problem described by the time-delay sampled-data system (10) under disturbance (24) respecting the average performance index 
(25). The optimal vibration control law is existent and unique and given by

$$
\begin{aligned}
u^{*}\left[t_{k}\right]= & -R^{-1} \bar{B}^{T}\left(T \bar{A}^{T}+I\right)^{-1} \\
& \times\left\{( P - T Q ) \left[x\left(t_{k-d_{2}}\right)+\sum_{i=k-h_{1}}^{k-1} A_{z}^{k-1-i} \bar{B}_{1} u\left[t_{i}\right]\right.\right. \\
& \left.+\sum_{j=k-h_{1}-1}^{k-1} A_{z}^{k-1-j} \bar{B}_{2} u\left[t_{j}\right]\right] \\
& \left.+P_{1} w\left(t_{k-d_{2}}\right)\right\},
\end{aligned}
$$

where $P$ is the unique positive definite solution of Riccati equation:

$$
\left(T \bar{A}^{T}+I\right) P\left(I+T \bar{B} R^{-1} \bar{B}^{T} P\right)^{-1}(T \bar{A}+I)+T Q=P,
$$

$P_{1}$ is the unique solution of Stein equation:

$$
\begin{gathered}
\left(T \bar{A}^{T}+I\right) T\left[I-T P\left(I+T \bar{B} R^{-1} \bar{B}^{T} P\right)^{-1} \bar{B} R^{-1} \bar{B}^{T}\right] P_{1} \bar{G}-P_{1} \\
=-T\left(T \bar{A}^{T}+I\right) P\left(I+T \bar{B} R^{-1} \bar{B}^{T} P\right)^{-1} \bar{D} F
\end{gathered}
$$

Proof. According to Pontryagin's minimum principle, the optimal control problem combined by the system (18) and the performance index (25) results in the two-point boundary value problem in delta-operator form:

$$
\begin{gathered}
{\left[\begin{array}{l}
\delta z\left(t_{k-d_{2}}\right) \\
\delta \lambda\left(t_{k-d_{2}}\right)
\end{array}\right]=} \\
+\left[\begin{array}{cc}
\bar{A} & -\bar{B} R^{-1} \bar{B}^{T} \\
-Q & -\bar{A}^{T}
\end{array}\right]\left[\begin{array}{c}
z\left(t_{k-d_{2}}\right) \\
\lambda\left(t_{k+1-d_{2}}\right)
\end{array}\right] \\
+\left[\begin{array}{c}
\bar{D} \\
0
\end{array}\right] v\left(t_{k-d_{2}}\right), \\
{\left[\begin{array}{c}
z\left(t_{-d_{2}}\right) \\
\lambda\left(t_{\infty}\right)
\end{array}\right]=\left[\begin{array}{c}
\alpha_{0} \\
0
\end{array}\right],}
\end{gathered}
$$

which yields

$$
\begin{aligned}
z\left(t_{k+1-d_{2}}\right)= & (T \bar{A}+I) z\left(t_{k-d_{2}}\right) \\
& -T \bar{B} R^{-1} \bar{B}^{T} \lambda\left(t_{k+1-d_{2}}\right)+\bar{D} v\left(t_{k-d_{2}}\right), \\
\lambda\left(t_{k-d_{2}}\right)= & T Q z\left(t_{k-d_{2}}\right)+\left(T \bar{A}^{T}+I\right) \lambda\left(t_{k+1-d_{2}}\right),
\end{aligned}
$$

with the optimal control law

$$
u^{*}\left[t_{k}\right]=-R^{-1} \bar{B}^{T} \lambda\left(t_{k+1-d_{2}}\right) .
$$

From (31) or (32a) and (32b) it is clear that $\lambda$ and $z$ are the linear relationship, so denote the costate vector

$$
\lambda\left(t_{k-d_{2}}\right)=P z\left(t_{k-d_{2}}\right)+P_{1} w\left(t_{k-d_{2}}\right) .
$$

Consequently, on one hand, together with (34) and (32a), it gives

$$
\begin{aligned}
z\left(t_{k+1-d_{2}}\right)= & (I+ \\
& \left.+\bar{B} R^{-1} \bar{B}^{T} P\right)^{-1} \\
& \times\left[(T \bar{A}+I) z\left(t_{k-d_{2}}\right)\right. \\
& \left.\quad+\left(\bar{D} F-\bar{B} R^{-1} \bar{B}^{T} P_{1} \bar{G}\right) w\left(t_{k-d_{2}}\right)\right] .
\end{aligned}
$$

On the other hand, from (34) and (32b), the following equation holds:

$$
\begin{aligned}
(P-T Q) z\left(t_{k-d_{2}}\right)= & \left(T \bar{A}^{T}+I\right) P z\left(t_{k+1-d_{2}}\right) \\
& +\left[\left(T \bar{A}^{T}+I\right) P_{1} \bar{G}-P_{1}\right] w\left(t_{k-d_{2}}\right)
\end{aligned}
$$

Substituting (35) into (36) yields

$$
\begin{aligned}
& {\left[\left(T \bar{A}^{T}+I\right) P\left(I+T \bar{B} R^{-1} \bar{B}^{T} P\right)^{-1}\right.} \\
& \times(T \bar{A}+I)+T Q-P] z\left(t_{k-d_{2}}\right) \\
& +\left[\left(T \bar{A}^{T}+I\right) P_{1} \bar{G}-P_{1}\right. \\
& \quad-\left(T \bar{A}^{T}+I\right) P\left(I+T \bar{B} R^{-1} \bar{B}^{T} P\right)^{-1} \\
& \left.\quad \times T\left(\bar{B} R^{-1} \bar{B}^{T} P_{1} \bar{G}-\bar{D} F\right)\right] w\left(t_{k-d_{2}}\right)=0 .
\end{aligned}
$$

Due to $z\left(t_{k-d_{2}}\right)$ and $w\left(t_{k-d_{2}}\right)$ arbitrarily satisfying (37), it results in Riccati equation (29) and Stein equation (30).

Further, the uniqueness is to be proved. According to linear optimal regulator theory, there exists a unique positive definite solution $P$ for Riccati equation (26) and the closedloop system of (18) is asymptotically stable, which implies that matrix

$$
(T \bar{A}+I)^{T} T\left[I-T P\left(I+T \bar{B} R^{-1} \bar{B}^{T} P\right)^{-1} \bar{B} R^{-1} \bar{B}^{T}\right]
$$

is Hurwitz, that is,

$$
\begin{aligned}
& \left|T \mu_{i}\left((T \bar{A}+I)^{T} T\left[I-T P\left(I+T \bar{B} R^{-1} \bar{B}^{T} P\right)^{-1} \bar{B} R^{-1} \bar{B}^{T}\right]\right)+1\right| \\
& \quad<1
\end{aligned}
$$

for $i=1,2, \ldots, n$. Moreover, since road disturbances are persistent and not asymptotically stable, this means that

$$
\left|T \mu_{j}(\bar{G})+1\right|=1
$$




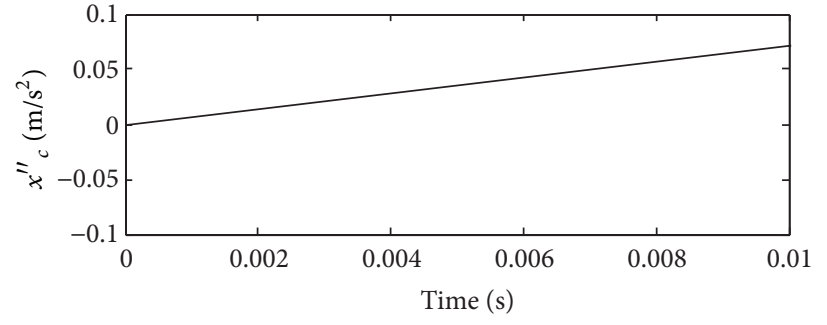

(a) Sprung mass acceleration

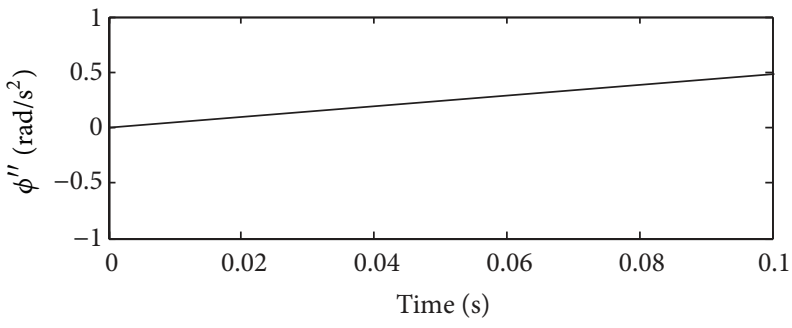

(b) Suspension acceleration

Figure 2: Acceleration responses of OLS.

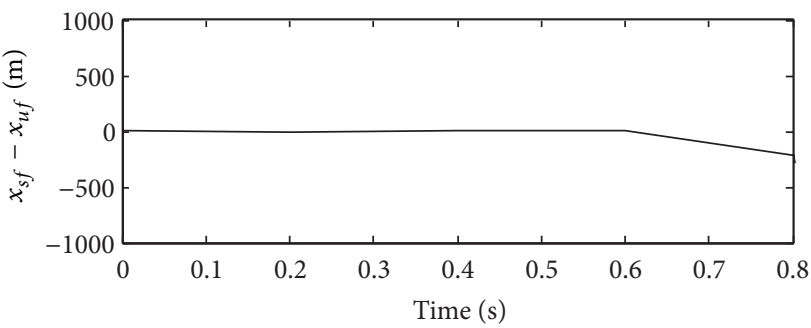

(a) Front suspension deflection

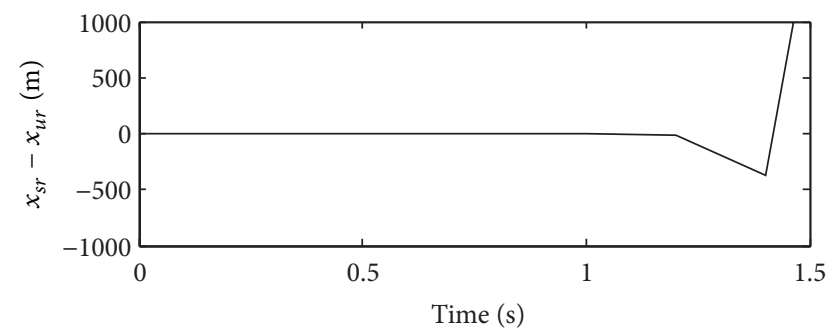

(b) Rear suspension deflection

FIgURE 3: Suspension deflection responses of OLS.

for $j=1,2, \ldots, p$. Therefore, from (39) and (40), the following inequality holds:

$$
\begin{aligned}
& \mid\left[T \mu _ { i } \left((T \bar{A}+I)^{T} T\right.\right. \\
& \left.\left.\quad \times\left[I-T P\left(I+T \bar{B} R^{-1} \bar{B}^{T} P\right)^{-1} \bar{B} R^{-1} \bar{B}^{T}\right]\right)+1\right] \\
& \cdot\left[T \mu_{j}(\bar{G})+1\right] \mid<1 .
\end{aligned}
$$

As a result, Stein equation (30) has the unique solution matrix $P_{1}$ [16]. The uniqueness of $P$ and $P_{1}$ leads to the uniqueness of OVC (28). This ends the proof.

3.2. Physical Realization of OVC. The optimal control law $u^{*}\left[t_{k}\right]$ (28) contains the physically unrealizable disturbance state $w\left(t_{k-d_{2}}\right)$ and some unmeasurable variables in $x\left(t_{k-d_{2}}\right)$ for economical or practical reasons. In this case, a reduced-order observer can be constructed to reconstruct theses states. Defining the augmented vector $\zeta\left(t_{k-d_{2}}\right)=$ $\left[z^{T}\left(t_{k-d_{2}}\right), w^{T}\left(t_{k-d_{2}}\right)\right]^{T}$ and $\eta\left(t_{k-d_{2}}\right)=\left[\bar{y}_{m}^{T}\left(t_{k}\right), v^{T}\left(t_{k-d_{2}}\right)\right]^{T}$ yields the following augmented system in delta domain combined by (18) and (24):

$$
\begin{gathered}
\delta \zeta\left(t_{k-d_{2}}\right)=\widetilde{A} \zeta\left(t_{k-d_{2}}\right)+\widetilde{B} u\left[t_{k}\right], \\
\eta\left(t_{k-d_{2}}\right)=\widetilde{C} \zeta\left(t_{k-d_{2}}\right),
\end{gathered}
$$

with

$$
\widetilde{A}=\left[\begin{array}{cc}
\bar{A} & \bar{D} F \\
0 & \bar{G}
\end{array}\right], \quad \widetilde{B}=\left[\begin{array}{l}
\bar{B} \\
0
\end{array}\right], \quad \widetilde{C}=\left[\begin{array}{cc}
\bar{C}_{1} & 0 \\
0 & F
\end{array}\right] .
$$

The pair $(\widetilde{A}, \widetilde{C})$ can be proved to be completely observable.

Choosing an arbitrary matrix $H$ such that $\Gamma=\left[\begin{array}{ll}\widetilde{C}^{T} & H^{T}\end{array}\right]^{T}$ is nonsingular and defining $\Pi=\Gamma^{-1}=\left[\begin{array}{ll}\Pi_{1} & \Pi_{2}\end{array}\right]$ give $\widetilde{C} \Gamma^{-1}=$ $\left[\begin{array}{ll}I & 0\end{array}\right]$. Let the nonsingular transformation be as follows:

$$
\bar{\zeta}\left(t_{k-d_{2}}\right)=\Gamma \zeta\left(t_{k-d_{2}}\right) \triangleq\left[\begin{array}{l}
\bar{\zeta}_{1}\left(t_{k-d_{2}}\right) \\
\bar{\zeta}_{2}\left(t_{k-d_{2}}\right)
\end{array}\right]
$$

where $\eta\left(t_{k-d_{2}}\right)=\bar{\zeta}_{1}\left(t_{k-d_{2}}\right)$. The new state equations follow in the delta-domain form:

$$
\begin{aligned}
\delta \bar{\zeta}_{2}\left(t_{k-d_{2}}\right) & =H \widetilde{A} \Pi_{2} \bar{\zeta}_{2}\left(t_{k-d_{2}}\right)+H \widetilde{A} \Pi_{1} \eta\left(t_{k-d_{2}}\right)+H \widetilde{B} u\left[t_{k}\right], \\
\delta \eta\left(t_{k-d_{2}}\right) & =\widetilde{C} \widetilde{A} \Pi_{2} \bar{\zeta}_{2}\left(t_{k-d_{2}}\right)+\widetilde{C} \widetilde{A} \Pi_{1} \eta\left(t_{k-d_{2}}\right)+\widetilde{C} \widetilde{B} u\left[t_{k}\right]
\end{aligned}
$$

Defining a new variable

$$
\psi\left(t_{k-d_{2}}\right)=\bar{\zeta}_{2}\left(t_{k-d_{2}}\right)-L \eta\left(t_{k-d_{2}}\right)
$$

with $L$ the gain matrix to be selected, (46) and (45) give

$$
\begin{aligned}
\delta \psi\left(t_{k-d_{2}}\right)=(H-L \widetilde{C})[ & {\left[\widetilde{A} \Pi_{2} \psi\left(t_{k-d_{2}}\right)+\widetilde{A}\left(\Pi_{1}+\Pi_{2} L\right)\right.} \\
& \left.\times \eta\left(t_{k-d_{2}}\right)+\widetilde{B} u\left[t_{k}\right]\right], \\
\bar{\zeta}_{2}\left(t_{k-d_{2}}\right)=\psi & \left(t_{k-d_{2}}\right)+L \eta\left(t_{k-d_{2}}\right) .
\end{aligned}
$$




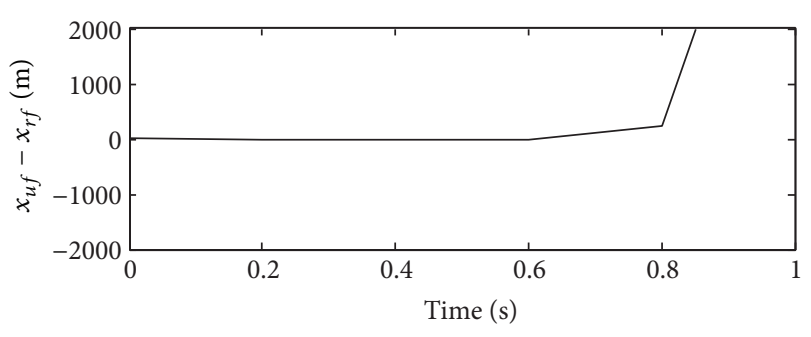

(a) Front tire deflection

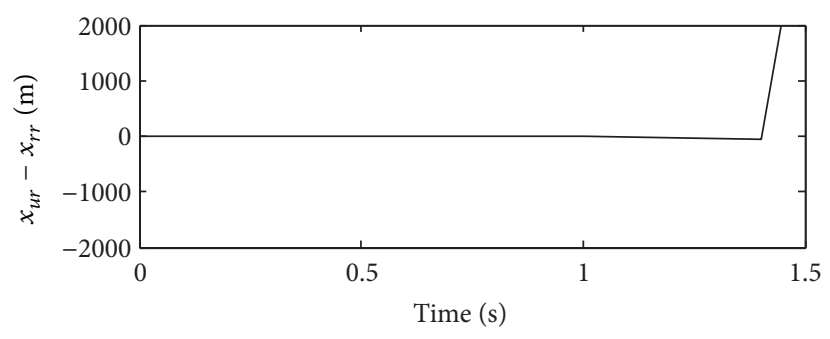

(b) Rear tire deflection

FIgURE 4: Tire deflection responses of OLS.

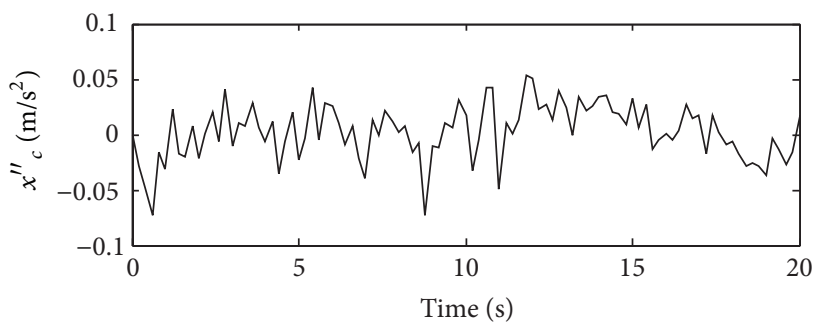

(a) Sprung mass acceleration

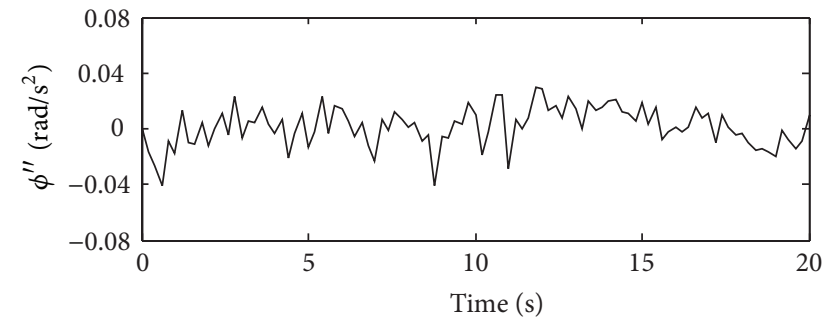

(b) Suspension acceleration

FIgURE 5: Acceleration responses under OVC with $\tau=0.015 \mathrm{~s}, \sigma=0.02 \mathrm{~s}$.

Noting that

$$
\zeta\left(t_{k-d_{2}}\right)=\Pi_{1} \eta\left(t_{k-d_{2}}\right)+\Pi_{2} \bar{\zeta}_{2}\left(t_{k-d_{2}}\right)
$$

and substituting (47) into (48) yield

$$
\begin{gathered}
\delta \psi\left(t_{k-d_{2}}\right)=(H-L \widetilde{C})\left[\widetilde{A} \Pi_{2} \psi\left(t_{k-d_{2}}\right)+\widetilde{A}\left(\Pi_{1}+\Pi_{2} L\right)\right. \\
\left.\times \eta\left(t_{k-d_{2}}\right)+\widetilde{B} u\left[t_{k}\right]\right], \\
\zeta\left(t_{k-d_{2}}\right)=\Pi_{2} \psi\left(t_{k-d_{2}}\right)+\left(\Pi_{1}+\Pi_{2} L\right) \eta\left(t_{k-d_{2}}\right) .
\end{gathered}
$$

Corresponding to (49), the reduced-order observer is constructed:

$$
\begin{gathered}
\delta \widehat{\psi}\left(t_{k-d_{2}}\right)=(H-L \widetilde{C})\left[\widetilde{A} \Pi_{2} \widehat{\psi}\left(t_{k-d_{2}}\right)+\widetilde{A}\left(\Pi_{1}+\Pi_{2} L\right)\right. \\
\left.\times \eta\left(t_{k-d_{2}}\right)+\widetilde{B} u\left[t_{k}\right]\right], \\
\widehat{\zeta}\left(t_{k-d_{2}}\right)=\Pi_{2} \widehat{\psi}\left(t_{k-d_{2}}\right)+\left(\Pi_{1}+\Pi_{2} L\right) \eta\left(t_{k-d_{2}}\right),
\end{gathered}
$$

where $\widehat{\psi}\left(t_{k-d_{2}}\right)$ and $\widehat{\zeta}\left(t_{k-d_{2}}\right)$ are the state and output of the observer, respectively. Denoting observer errors $\widetilde{\psi}\left(t_{k-d_{2}}\right)=$ $\widehat{\psi}\left(t_{k-d_{2}}\right)-\psi\left(t_{k-d_{2}}\right)$ and $e\left(t_{k-d_{2}}\right)=\widehat{\zeta}\left(t_{k-d_{2}}\right)-\zeta\left(t_{k-d_{2}}\right)$, from (50) and (49), the error state equation is got:

$$
\begin{gathered}
\delta \widetilde{\psi}\left(t_{k-d_{2}}\right)=(H-L \widetilde{C}) \widetilde{A} \Pi_{2} \widetilde{\psi}\left(t_{k-d_{2}}\right), \\
e\left(t_{k-d_{2}}\right)=\Pi_{2} \widetilde{\psi}\left(t_{k-d_{2}}\right) .
\end{gathered}
$$

Hence, the error equation gain $L$ should be regulated to make (51) asymptotically stable, such that $\lim _{k \rightarrow \infty} e\left(t_{k-d_{2}}\right)=0$.
The observable pair $(\widetilde{A}, \widetilde{C})$ results in the observable pair $\left(\widetilde{C} \widetilde{A} \Pi_{2}, H \widetilde{A} \Pi_{2}\right)$. Consequentially, the gain $L$ is enabled to make the eigenvalues of $(H-L \widetilde{C}) \widetilde{A} \Pi_{2}$ assigned in the lefthalf complex plane, which means that error equation (51) is asymptotically stable. Therefore, the reconstructed states can replace the unavailable ones. Through this mean, states in OVC (28) are replaced by the augmented state

$$
u\left[t_{k}\right]=-R^{-1} \bar{B}^{T}\left(T \bar{A}^{T}+I\right)^{-1}\left[P-T Q \quad P_{1}\right] \widehat{\zeta}\left(t_{k-d_{2}}\right),
$$

which gives the dynamical control law

$$
\begin{aligned}
\delta \widehat{\psi}\left(t_{k-d_{2}}\right)=(H-L \widetilde{C})\left[\widetilde{A} \Pi_{2} \widehat{\psi}\left(t_{k-d_{2}}\right)+\widetilde{A}\left(\Pi_{2} L+\Pi_{1}\right)\right. & \left.\times \eta\left(t_{k-d_{2}}\right)+\widetilde{B} u\left[t_{k}\right]\right], \\
u\left[t_{k}\right]=- & R^{-1} \bar{B}^{T}\left(T \bar{A}^{T}+I\right)^{-1}\left[P-T Q P_{1}\right] \\
\times & {\left[\Pi_{2} \widehat{\psi}\left(t_{k-d_{2}}\right)+\left(\Pi_{1}+\Pi_{2} L\right) \eta\left(t_{k-d_{2}}\right)\right], }
\end{aligned}
$$

with $\eta\left(t_{k-d_{2}}\right)=\left[\bar{y}_{m}^{T}\left(t_{k}\right), v^{T}\left(t_{k-d_{2}}\right)\right]^{T}$ in which $\bar{y}_{m}\left(t_{k}\right)$ is defined in (16).

\section{Simulation Examples}

In this section, a half-car suspension model will be employed to carry out the simulations. We will take two cases of the simulations: firstly, to demonstrate the closed-loop matrices of the continues time, discrete time, and the delta domain taking different sampling period $T$ in order to verify the deltadomain matrix enables approximating to the continues-time 


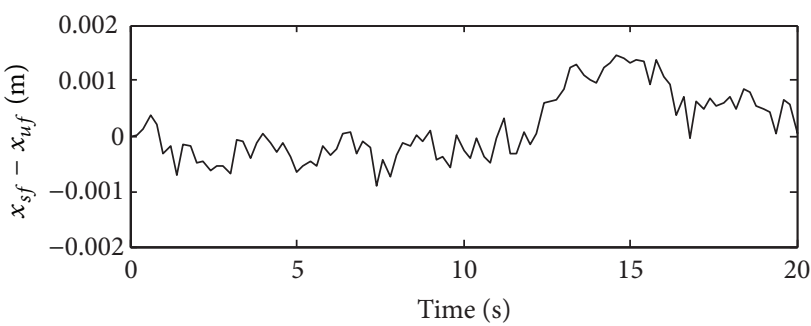

(a) Front suspension deflection

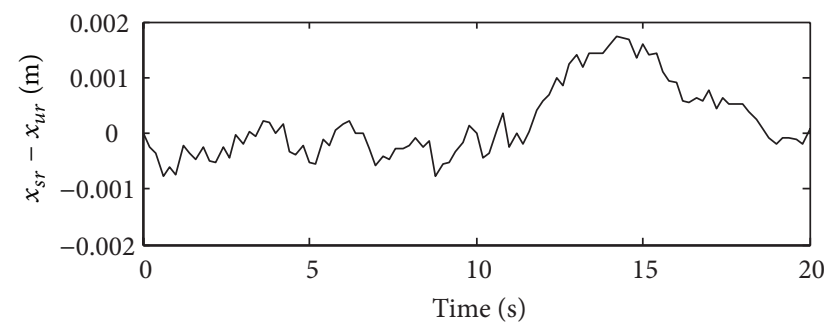

(b) Rear suspension deflection

FIGURE 6: Suspension deflection responses under OVC with $\tau=0.015 \mathrm{~s}, \sigma=0.02 \mathrm{~s}$.

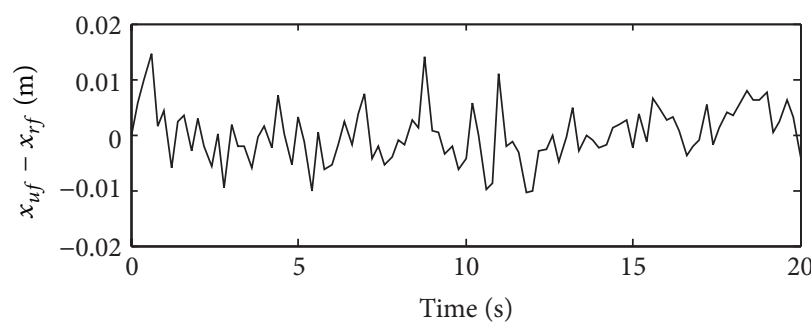

(a) Front tire deflection

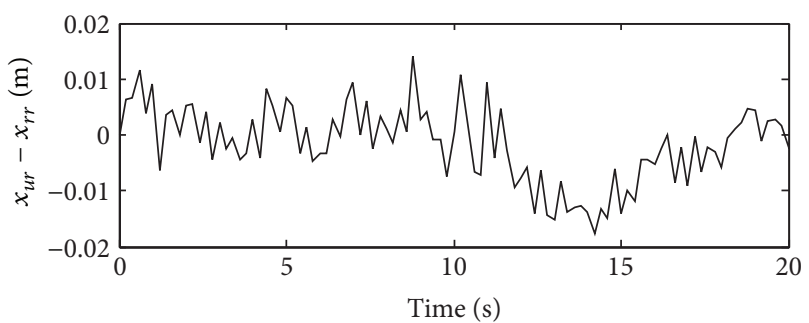

(b) Rear tire deflection

Figure 7: Tire deflection responses under OVC with $\tau=0.015 \mathrm{~s}, \sigma=0.02 \mathrm{~s}$.

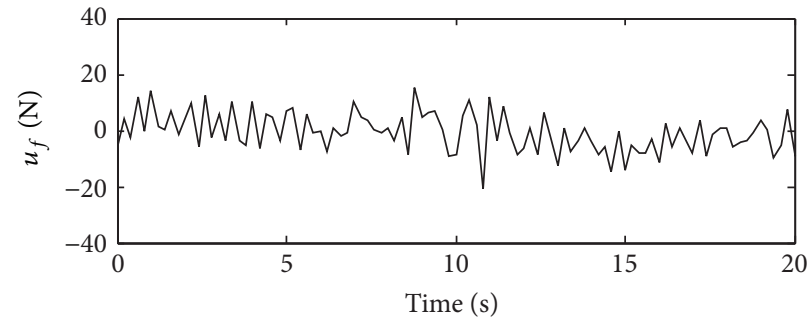

(a) Front control force

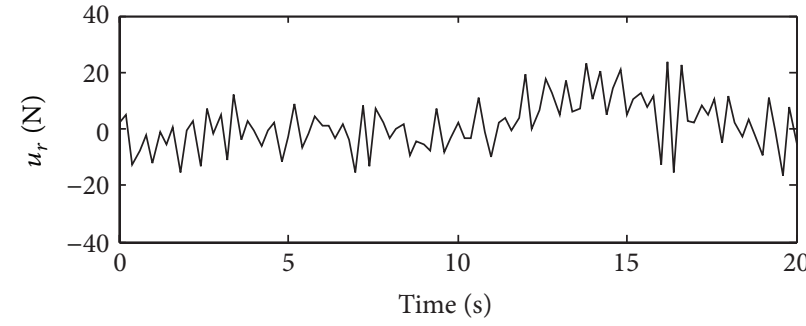

(b) Rear control force

FIgURE 8: Control inputs of OVC with $\tau=0.015 \mathrm{~s}, \sigma=0.02 \mathrm{~s}$.

TABLE 2: Parameters of a half-car suspension.

\begin{tabular}{|c|c|c|c|}
\hline Parameter & Variable & Value & Unit \\
\hline Sprung mass & $m_{s}$ & 500 & $\mathrm{Kg}$ \\
\hline Sprung mass moment of inertia about pitch axis & $I$ & 910 & $\mathrm{Kg} \cdot \mathrm{m}^{2}$ \\
\hline Front unsprung mass & $m_{u f}$ & 30 & $\mathrm{Kg}$ \\
\hline Rear unsprung mass & $m_{u r}$ & 40 & $\mathrm{Kg}$ \\
\hline Front suspension spring & $k_{f}$ & 10,000 & $\mathrm{~N} / \mathrm{m}$ \\
\hline Rear suspension spring & $k_{r}$ & 10,000 & $\mathrm{~N} / \mathrm{m}$ \\
\hline Front tire spring & $k_{t f}$ & 100,000 & $\mathrm{~N} / \mathrm{m}$ \\
\hline Rear tire spring & $k_{t r}$ & 100,000 & $\mathrm{~N} / \mathrm{m}$ \\
\hline Front suspension damper & $b_{f}$ & 1,000 & $\mathrm{~N} \cdot \mathrm{s} / \mathrm{m}$ \\
\hline Rear suspension damper & $b_{r}$ & 1,000 & $\mathrm{~N} \cdot \mathrm{s} / \mathrm{m}$ \\
\hline Distance from the center of mass to the front suspension attachment point & $l_{f}$ & 1.25 & M \\
\hline Distance from the center of mass to the rear suspension attachment point & $l_{r}$ & 1.45 & $\mathrm{M}$ \\
\hline
\end{tabular}


one as $T$ decreases; secondly, to apply the designed OVC to the half-car suspension model with delays comparing with the OLS in order to verify that the OVC guarantees the system stability and the desired suspension performance. The parameter values are shown in Table 2 (refer to in [15]).

To generate $\mathrm{D}$ Grade road profile, select $C_{s}=64 \times$ $10^{-7} \mathrm{~m}^{3} / \mathrm{rad}$ and $k=3$. Setting $v_{0}=20 \mathrm{~m} / \mathrm{s}, l=400 \mathrm{~m}$, and $p=200$ in (20) takes the frequency band from $0.05 \mathrm{~Hz}$ to $20 \mathrm{~Hz}$. Take the performance index (24) with $q_{1}=q_{2}=10$, $q_{3}=q_{4}=10^{3}, q_{5}=q_{6}=100, r_{1}=r_{2}=10^{-3}$, and delays $\tau=0.015 \mathrm{~s}, \sigma=0.02 \mathrm{~s}$.

Case 1. Taking different sampling periods $T=2 \mathrm{~ms}, 0.2 \mathrm{~ms}$, $0.02 \mathrm{~ms}$, the relative closed-loop matrices of continues-time $A_{c}$, discrete-time $A_{c z}$, and delta-domain $A_{c \delta}$ are listed from (54) to (56c); respectively.

(i) $A_{c}$ is the continuous-time closed-loop matrix:

$$
A_{c}=\left[\begin{array}{cccccccc}
-7.2 & 135.7 & -18.4 & 260.9 & -0.8 & 380.6 & -5 & -0.5 \\
-17.6 & 113.6 & 118.1 & 221.3 & -3.2 & 368.7 & -1.1 & -1.8 \\
4.5 & -16.7 & -39.8 & -32.9 & 0.7 & -62.1 & 0.8 & 0.2 \\
17.4 & -111.9 & -116.7 & -218.1 & 3.1 & -362.3 & 1.1 & 1.7 \\
141 & -2223.8 & -418.1 & -4215.2 & 34.5 & -7390.5 & 56 & 13.8 \\
-1.9 & 12.8 & 13.5 & 19 & -0.3 & 33 & 0 & -0.4 \\
544.3 & -127.5 & -5667.5 & -295.7 & 63.7 & -1220.3 & -2.3 & 6.3 \\
148.9 & -711.3 & -995.1 & -4372.8 & 26.7 & -3084.4 & 9.4 & -18.7
\end{array}\right]
$$

(ii) $A_{c z}$ is the discrete-time closed-loop matrix setting $T=$ $2 \mathrm{~ms}, 0.2 \mathrm{~ms}, 0.02 \mathrm{~ms}$ :

$$
\begin{aligned}
& T=2 \mathrm{~ms}, \\
& A_{c z}=\left[\begin{array}{cccccccc}
0.9826 & 0.2581 & 0.0035 & 0.4948 & -0.0019 & 0.7223 & -0.0098 & -0.0009 \\
-0.0342 & 1.2207 & 0.2305 & 0.4353 & -0.0061 & 0.7161 & -0.0020 & -0.0034 \\
0.0094 & -0.0325 & 0.9160 & -0.0644 & 0.0015 & -0.1222 & 0.0015 & 0.0003 \\
0.0337 & -0.2174 & -0.2277 & 0.5710 & 0.0061 & -0.7038 & 0.0020 & 0.0034 \\
0.3096 & -4.3354 & -1.2278 & -8.2039 & 1.0709 & -14.4298 & 0.1099 & 0.0272 \\
-0.0037 & 0.0260 & 0.0266 & 0.0406 & -0.0006 & 1.0675 & -0.0001 & -0.0008 \\
1.0441 & -0.2057 & -10.9210 & -0.5015 & 0.1222 & -2.2585 & 0.9883 & 0.0121 \\
0.1870 & -0.7301 & -1.2585 & -7.2354 & 0.0336 & -3.8741 & 0.0112 & 0.9538
\end{array}\right], \\
& T=0.2 \mathrm{~ms} \text {, } \\
& A_{c z}=\left[\begin{array}{cccccccc}
0.9985 & 0.0270 & -0.0033 & 0.0519 & -0.0002 & 0.0757 & -0.0010 & -0.0001 \\
-0.0035 & 1.0227 & 0.0236 & 0.0442 & -0.0006 & 0.0735 & -0.0002 & -0.0003 \\
0.0009 & -0.0033 & 0.9920 & -0.0066 & 0.0001 & -0.0124 & 0.0002 & 0.0000 \\
0.0035 & -0.0223 & -0.0233 & 0.9565 & 0.0006 & -0.0723 & 0.0002 & 0.0003 \\
0.0285 & -0.4436 & -0.0877 & -0.8408 & 1.0069 & -1.4746 & 0.0112 & 0.0028 \\
-0.0004 & 0.0026 & 0.0027 & 0.0038 & -0.0001 & 1.0066 & 0.0000 & -0.0001 \\
0.1084 & -0.0250 & -1.1295 & -0.0582 & 0.0127 & -0.2422 & 0.9995 & 0.0013 \\
0.0286 & -0.1351 & -0.1915 & -0.8591 & 0.0051 & -0.5932 & 0.0018 & 0.9962
\end{array}\right], \\
& T=0.02 \mathrm{~ms}, \\
& A_{c z}=\left[\begin{array}{cccccccc}
0.9999 & 0.0027 & -0.0004 & 0.0052 & 0.0000 & 0.0076 & -0.0001 & 0.0000 \\
-0.0004 & 1.0023 & 0.0024 & 0.0044 & -0.0001 & 0.0074 & 0.0000 & 0.0000 \\
0.0001 & -0.0003 & 0.9992 & -0.0007 & 0.0000 & -0.0012 & 0.0000 & 0.0000 \\
0.0003 & -0.0022 & -0.0023 & 0.9956 & 0.0001 & -0.0072 & 0.0000 & 0.0000 \\
0.0028 & -0.0445 & -0.0084 & -0.0843 & 1.0007 & -0.1478 & 0.0011 & 0.0003 \\
0.0000 & 0.0003 & 0.0003 & 0.0004 & 0.0000 & 1.0007 & 0.0000 & 0.0000 \\
0.0109 & -0.0025 & -0.1133 & -0.0059 & 0.0013 & -0.0244 & 1.0000 & 0.0001 \\
0.0030 & -0.0142 & -0.0198 & -0.0873 & 0.0005 & -0.0615 & 0.0002 & 0.9996
\end{array}\right] .
\end{aligned}
$$


(iii) $A_{c \delta}$ is the delta-domain closed-loop matrix setting $T=2 \mathrm{~ms}, 0.2 \mathrm{~ms}, 0.02 \mathrm{~ms}$ :

$$
\begin{aligned}
& T=2 \mathrm{~ms}, \\
& A_{c \delta}=\left[\begin{array}{cccccccc}
-8.7 & 129.1 & 1.7 & 247.4 & -0.9 & 361.2 & -4.9 & -0.5 \\
-17.1 & 110.4 & 115.2 & 217.7 & -3.1 & 358 & -1 & -1.7 \\
4.7 & -16.2 & -42 & -32.2 & 0.8 & -61.1 & 0.8 & 0.2 \\
16.9 & -108.7 & -113.8 & -214.5 & 3 & -351.9 & 1 & 1.7 \\
154.8 & -2167.7 & -613.9 & -4101.9 & 35.4 & -7214.9 & 55 & 13.6 \\
-1.9 & 13 & 13.3 & 20.3 & -0.3 & 33.7 & 0 & -0.4 \\
522 & -102.8 & -5460.5 & -250.7 & 61.1 & -1129.2 & -5.9 & 6 \\
93.5 & -365.1 & -629.3 & -3617.7 & 16.8 & -1937.1 & 5.6 & -23.1
\end{array}\right] \text {, } \\
& T=0.2 \mathrm{~ms} \text {, } \\
& A_{c \delta}=\left[\begin{array}{cccccccc}
-7.4 & 135 & -16.3 & 259.5 & -0.8 & 378.6 & -0.5 & -0.5 \\
-17.6 & 113.3 & 117.9 & 221 & -3.2 & 367.6 & -1.1 & -1.7 \\
4.6 & -16.6 & -40 & -32.9 & 0.7 & -62 & 0.8 & 0.2 \\
17.4 & -111.6 & -116.5 & -217.7 & 3.1 & -361.3 & 1.1 & 1.7 \\
142.5 & -2218.2 & -438.3 & -4203.8 & 34.6 & -7372.8 & 55.9 & 13.8 \\
-1.9 & 12.9 & 13.5 & 19.2 & -0.3 & 33.1 & 0 & -0.4 \\
542.2 & -125 & -5647.6 & -291.1 & 63.4 & -1211.2 & -2.7 & 6.3 \\
143.2 & -675.5 & -957.6 & -4295.4 & 25.7 & -2966.1 & 9 & -19.1
\end{array}\right] \text {, } \\
& T=0.02 \mathrm{~ms}, \\
& A_{c \delta}=\left[\begin{array}{cccccccc}
-7.2 & 135.6 & -18.2 & 260.8 & -0.8 & 380.4 & -5 & -0.5 \\
-17.6 & 113.6 & 118.1 & 221.3 & -3.2 & 368.6 & -1.1 & -1.8 \\
4.5 & -16.7 & -39.8 & -32.9 & 0.7 & -62.1 & 0.8 & 0.2 \\
17.4 & -111.9 & -116.7 & -218 & 3.1 & -362.2 & 1.1 & 1.7 \\
141.2 & -2223.3 & -420.2 & -4214.1 & 34.6 & -7388.7 & 56 & 13.8 \\
-1.9 & 12.8 & 13.5 & 19 & -0.3 & 33 & 0 & -0.4 \\
544.1 & -127.2 & -5665.5 & -295.2 & 63.7 & -1219.4 & -2.3 & 6.3 \\
148.3 & -707.7 & -991.3 & -4365 & 26.6 & -3072.6 & 9.4 & -18.7
\end{array}\right] .
\end{aligned}
$$

Comparing with the continuous-time closed-loop matrix (54), from (55a) to (55c) we can see the discretized matrices approach to the unit matrix as the sampling period $T$ decreases; from (56a) to (56c) we can see that the deltadomain matrices approach to the original continuous-time matrix (54) as $T$ decreases. Evidently, the delta-domain approach is more appropriate for the high-sampling IVNs system.

Case 2. Setting sampling period $T=0.2 \mathrm{~s}$ and comparing with the responses of the accelerations, deflections of suspension and tire, and control input of OLS shown in Figures 2,3 , and 4, the suspension responses controlled by OVC are shown in Figures 5, 6, 7, and 8.

System responses in Figures 2-4 show that they diverged when without control (of OLS). On the contrary, in Figures 5-8, when the suspension was controlled under OVC, the suspension responses were stabilized. Moreover, they achieved relatively low magnitude and satisfied the desired requirement.

\section{Conclusions}

This paper has presented the OVC design for sampleddata system with time delays with its application to a half-car suspension using delta-domain approach. Through this approach, the built model provides more realistic and appropriate property. The delay compensators guarantee the closed-loop stability and requested performance. The simulation has demonstrated that the designed controller can efficiently make the system performance achieve the desired goal and the design approach proposed in this study is effective and feasible.

\section{Acknowledgments}

This work was supported in part by the China Scholarship Council Foundation (201208535084), the Natural Science Foundation of Yunnan Province (2011FZ169), and the Open Fund of Key Laboratory in Software Engineering of Yunnan Province (2011SE15). 


\section{References}

[1] "Automotive: In-Vehicle Networking: Local Interconnect Network (LIN)," http://www.melexis.com/Application/In-VehicleNetworking-137.aspx.

[2] “CAN in automation," 2008, http://www.can-cia.org/ .

[3] “MOST specification rev.3.0”, 2008, http://www.mostnet.de/.

[4] J.-P. Richard, "Time-delay systems: an overview of some recent advances and open problems," Automatica, vol. 39, no. 10, pp. 1667-1694, 2003.

[5] H. Du and N. Zhang, " $H_{\infty}$ control of active vehicle suspensions with actuator time delay," Journal of Sound and Vibration, vol. 301, no. 1-2, pp. 236-252, 2007.

[6] H. Du, N. Zhang, and J. Lam, "Parameter-dependent inputdelayed control of uncertain vehicle suspensions," Journal of Sound and Vibration, vol. 317, no. 3-5, pp. 537-556, 2008.

[7] R. H. Middleton and G. C. Goodwin, "Improved finite word length charateristics in digital control using delta operators," IEEE Transactions on Automatic Control, vol. 31, no. 11, pp. 10151021, 1986.

[8] G. C. Goodwin, R. L. Leal, D. Q. Mayne, and R. H. Middleton, "Rapprochement between continuous and discrete model reference adaptive control," Automatica, vol. 22, no. 2, pp. 199-207, 1986.

[9] P. Suchomski, "A $J$-lossless coprime factorisation approach to $H_{\infty}$ control in delta domain," Automatica, vol. 38, no. 10, pp. 1807-1814, 2002.

[10] P. Suchomski, "Numerically robust delta-domain solutions to discrete-time Lyapunov equations," Systems \& Control Letters, vol. 47, no. 4, pp. 319-326, 2002.

[11] J. Lei, "Optimal vibration control for sampled-data systems with time-delays applying Delta-transform," Journal of Yunnan University: Natural Sciences Edition, vol. 34, no. 5, pp. 527-532, 2012 (Chinese).

[12] J. Lei, Study on optimal disturbance rejection methods for systems with control delay [M.E. Dissertation], Ocean University of China, Qingdao, China, 2007.

[13] J. Lei, Study on optimal vibration control for time delay systems with application to vehicle suspension systems [D.E. Dissertation], Ocean University of China, Qingdao, China, 2010.

[14] S. Mondié and W. Michiels, "Finite spectrum assignment of unstable time-delay systems with a safe implementation," IEEE Transactions on Automatic Control, vol. 48, no. 12, pp. 22072212, 2003.

[15] J. Marzbanrad, G. Ahmadi, H. Zohoor, and Y. Hojjat, "Stochastic optimal preview control of a vehicle suspension," Journal of Sound and Vibration, vol. 275, no. 3-5, pp. 973-990, 2004.

[16] S. K. Mitra, "The matrix equation $A X B+C X D=$ E," SIAM Journal on Applied Mathematics, vol. 32, no. 4, pp. 823-825, 1977. 


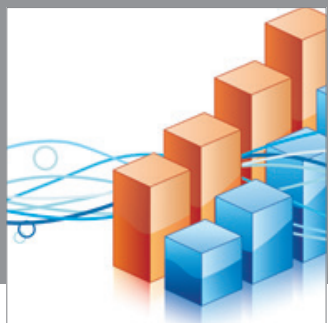

Advances in

Operations Research

mansans

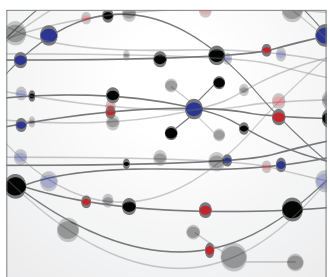

The Scientific World Journal
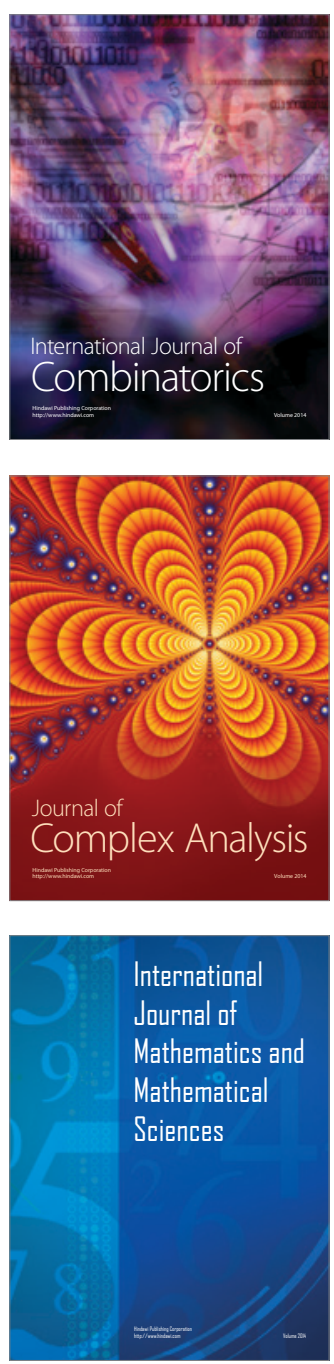
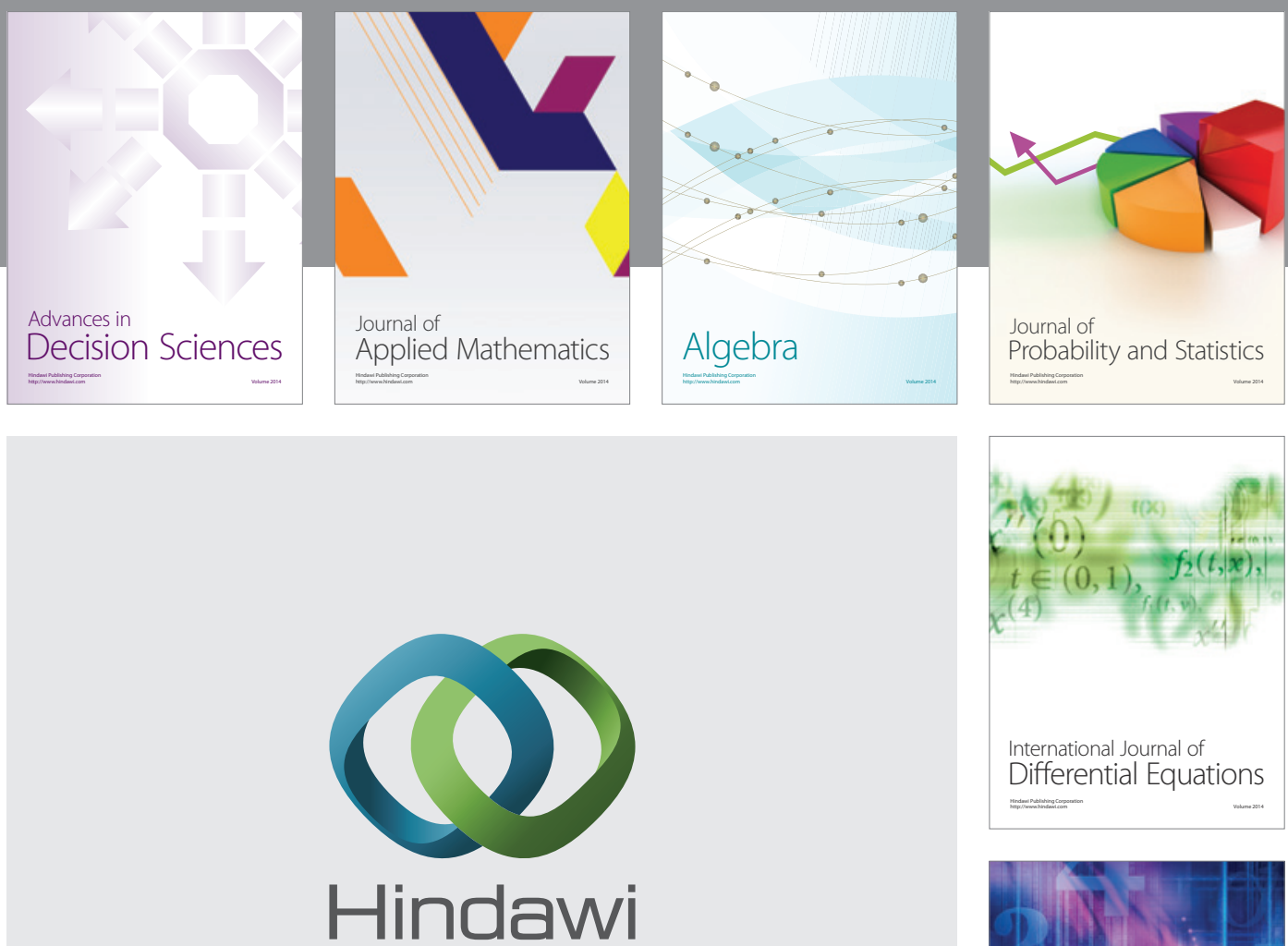

Submit your manuscripts at http://www.hindawi.com
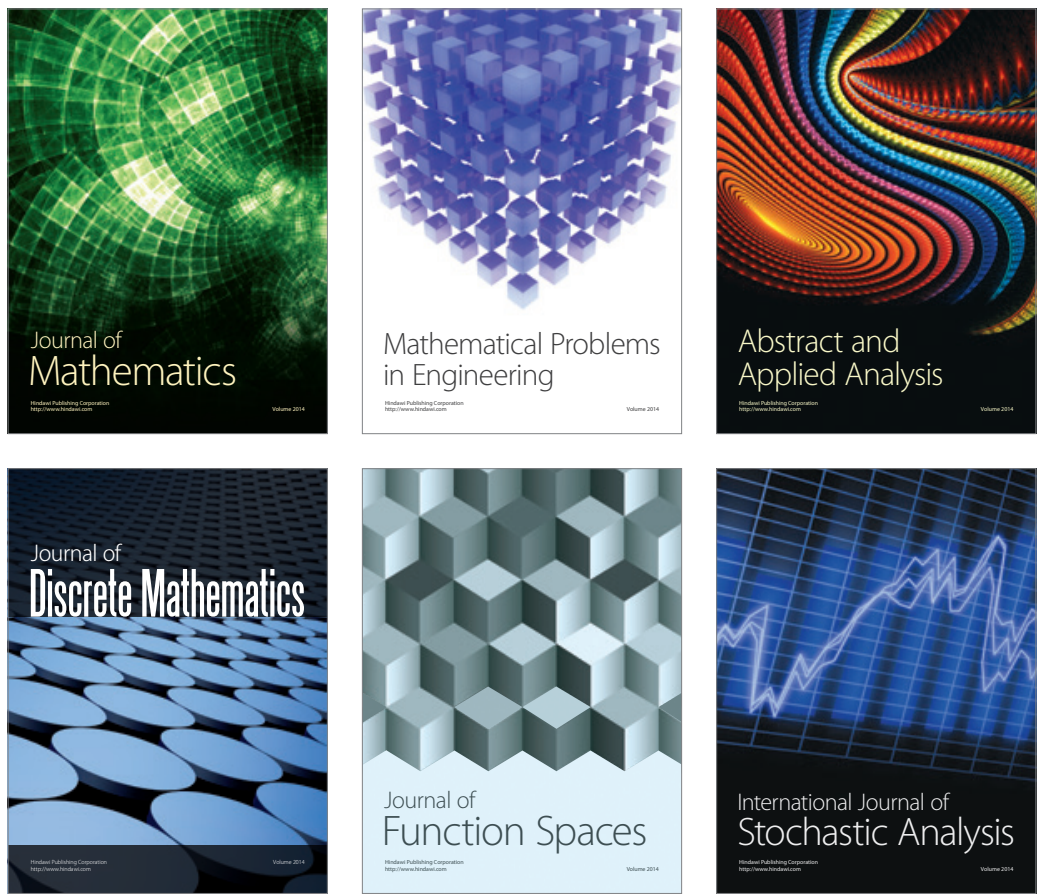

Journal of

Function Spaces

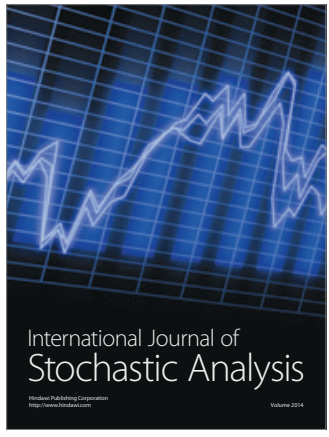

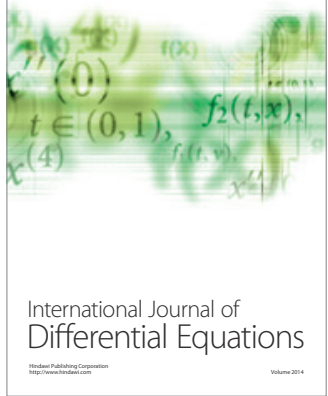
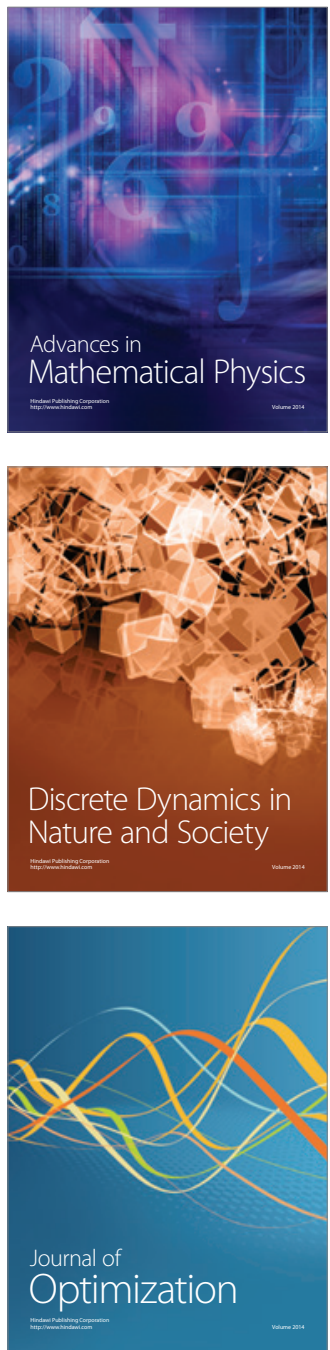